\title{
Sleep deprivation and obesity in shift workers in southern Brazil
}

\author{
Raquel Canuto ${ }^{1}$, Marcos Pascoal Pattussi ${ }^{2}$, Jamile Block Araldi Macagnan ${ }^{3}$, \\ Ruth Liane Henn ${ }^{2}$ and Maria Teresa Anselmo Olinto ${ }^{2,4, *}$ \\ 'Post-graduate Programme in Endocrinology, Federal University of Rio Grande do Sul State, Department of \\ Nutrition, University of Vale do Rio dos Sinos, São Leopoldo, RS, Brazil: ${ }^{2}$ Post-graduate Programme in Collective \\ Health, University of Vale do Rio dos Sinos, Av. Unisinos 950, CP 275, São Leopoldo, RS 93022-000, Brazil: \\ ${ }^{3}$ Department of Nursing, University of the State of Santa Catarina, Palmitos, SC, Brazil: ${ }^{4}$ Nutrition Department, \\ Federal University of Health Science of Porto Alegre, Porto Alegre, RS, Brazil
}

Submitted 23 April 2013: Final revision received 7 September 2013: Accepted 10 September 2013: First published online 29 0ctober 2013

\begin{abstract}
Objective: The objective of our study was to explore the association between sleep deprivation and obesity among shift workers.

Design: A cross-sectional study was conducted. Obesity was defined as BMI $\geq 30 \mathrm{~kg} / \mathrm{m}^{2}$. Time of sleep was categorized as: $>5 \mathrm{~h}$ of continuous sleep/d; $\leq 5 \mathrm{~h}$ of continuous sleep/d with some additional rest (sleep deprivation level I); and $\leq 5 \mathrm{~h}$ of continuous sleep/d without any additional rest (sleep deprivation level II). Sociodemographic, parental and behavioural variables were evaluated by means of a standardized pre-tested questionnaire. Potential confounding factors were controlled for in the multivariable model.

Setting: A poultry-processing plant in southern Brazil.

Subjects: Nine hundred and five shift workers (63\% female).

Results: Obesity was more prevalent in the participants who were female, aged 40 years and older, who had less schooling and reported excess weight in both parents. Sleep deprivation levels I and II were associated with increased income, number of meals consumed throughout the day and nightshift work. All of the workers who exhibited a degree of sleep deprivation worked the night shift. After controlling for potential confounding factors, the prevalence ratios of obesity were $1 \cdot 4(95 \%$ CI $0 \cdot 8,2 \cdot 2)$ and $4 \cdot 4(95 \%$ CI $2 \cdot 4,8 \cdot 0)$ in the workers with sleep deprivation levels I and II, respectively, compared with the reference group. Conclusions: These results show a strong association between sleep deprivation and obesity in shift workers and that sleep deprivation may be a direct consequence of working at night.
\end{abstract}

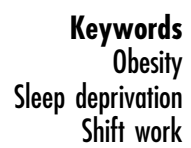

The number of people who are obese is increasing worldwide including in Brazil ${ }^{(1)}$. Recent data from the Family Budget Survey, carried out between 2008 and 2009, showed that in Brazil obesity affects approximately $14 \%$ of adults over the age of 20 years ${ }^{(2)}$. Obesity is linked to many adverse health outcomes, including diabetes, CVD, cancer and overall mortality ${ }^{(3-6)}$. Traditionally, causes of obesity have been linked to the imbalance between energy intake and physical activity ${ }^{(7)}$. However, modern life has led to other changes in human behaviour, such as shift work and sleep deprivation.

Shift work is becoming increasingly prevalent worldwide. There is no official estimate of the number of shift workers in Brazil. However, according to the results of a survey conducted in 2005 , more than $17 \%$ of the working population in the European Union are shift workers, with a significant variation among countries (from $6 \cdot 4 \%$ to $30 \cdot 0 \%)^{(8)}$. Many health impairments associated with shift work have been reported, but the most prevalent problem for the shift worker is the quantity and quality of sleep $^{(9-11)}$. Moreover, a number of studies have associated short sleep duration with higher BMI in adults ${ }^{(12,13)}$.

Despite the rapid growth of the labour force employed in large companies that function $24 \mathrm{~h} / \mathrm{d}$ in South American countries, until now few studies have investigated the consequences of sleep deprivation on obesity in this population $^{(10)}$. Thus, the objective of our study was to examine the association between sleep deprivation and obesity. The study was conducted among the employees of a poultry-processing plant in southern Brazil that functions $24 \mathrm{~h} / \mathrm{d}$.

\section{Methods}

The study was conducted among the employees of a large poultry-processing plant located in southern Brazil that functions $24 \mathrm{~h} / \mathrm{d}$. The employees worked on the plant's 
production line in three main sectors: evisceration, cutting room and thermoprocessing. The cross-sectional study included workers aged 18 to 50 years who had been working fixed shifts for more than 6 months on the plant production line. Pregnant women and employees who had not worked for more than $10 \mathrm{~d}$ were excluded from the sample.

The company employed 2645 workers, men and women, who lived in the headquartered municipality or in six other neighbouring municipalities. For logistical reasons, such as distance and urban area, all of the employees living in the headquartered municipality $(n 710)$ and in the two closest municipalities ( $n$ 195) were included, summing to a sample size of 905 workers. An a posteriori calculation of power was performed: considering an $80 \%$ power and a significance level of $5 \%$, this sample had the power to show differences of $50 \%$ in the obesity prevalence rate between sleep deprivation categories.

Obesity was assessed by BMI, which was calculated by dividing the participants' weight (in kilograms) by the square of their height (in metres). Weight measurements (in kilograms) were made using a Plataform Toledo scale, digital model 2096PP (São Paulo, Brazil) which can accurately measure up to $200 \mathrm{~kg}$, and height measurements (in centimetres) were obtained using a Seca Bodimeter 208 (Hamburg, Germany) portable stadiometer with scale increments of $1 \mathrm{~mm}$. The BMI cut-off point for obesity was $\geq 30 \mathrm{~kg} / \mathrm{m}^{2}$.

Sociodemographic, parental overweight, behavioural and sleep characteristics were evaluated using a standardized pre-tested questionnaire. All interviews were conducted in the workers' homes between January and May 2010. The sociodemographic variables were age (continuous variable categorized into quintiles), skin colour (self-reported by the interviewees and categorized as 'white' or 'other'), marital status (classified as 'having a partner' or 'not having a partner'), years of education (categorized as ' $1-4$ years of elementary school', '5-8 years of elementary school', 'did not complete high school' or 'completed high school and higher') and total family income (continuous data categorized into quartiles). The parental overweight status as reported by the interviewee was categorized as obesity in 'neither parent', in 'one parent' or in 'both parents'. The behavioural variables were: leisure physical activity ('active' individuals doing physical activity for $\geq 150 \mathrm{~min} /$ week and 'inactive' individuals doing $<150 \mathrm{~min} /$ week) ${ }^{(14)}$ and the number of meals per day (one or two meals, three meals, four or more meals). Sleep deprivation was measured by hours of sleep and categorized as $>5 \mathrm{~h}$ of continuous sleep/d, $\leq 5 \mathrm{~h}$ of continuous sleep/d with some additional rest (sleep deprivation level $\mathrm{I}$ ) and $\leq 5 \mathrm{~h}$ of continuous sleep/d without any additional rest (sleep deprivation level II). The work schedule was provided by the company and confirmed by the workers through a questionnaire.
All participants were permanent shift workers. Those who worked more than $90 \%$ of their hours in the evening or at night were considered to be exposed (i.e. those who started their shift after 17.00 hours). Dayshift workers who started their working hours between 06.00 and 14.15 hours were considered to be non-exposed. Also collected was the period of time (in months) that the employee had worked in the current work shift.

Data were entered into Epidata software with double data entry. Data analysis was performed using the statistical software package STATA version $11 \cdot 0$. Estimates for crude and adjusted prevalence ratios with $95 \%$ confidence intervals were calculated by modified Poisson regression with robust variance. Model 1 was unadjusted. Model 2 was adjusted for demographic and socio-economic variables. Model 3 was adjusted for model 2 and parental overweight status. Model 4 was adjusted for models 2 and 3 and behavioural variables (physical activity, number of meals per day, work shift and period in the current shift). Variables were retained in models as potential confounding factors if they had a $P$ value of $<0 \cdot 20$.

This project was approved by the Research Ethics Committee of the University of Vale do Rio dos Sinos, RS, Brazil, as recommended by resolution 196/96 which relates to human research.

\section{Results}

The mean age of the participants was 31 (SD 8.7) years and $63 \%$ were female. A total of $10 \cdot 8 \%$ of the workers were obese $(95 \%$ CI $8 \cdot 7,12 \cdot 8 \%)$. The prevalence of sleep deprivation levels I and II was $18 \cdot 0 \%$ (95\% CI 16.0, $20 \cdot 3 \%)$ and $1 \cdot 8 \%(95 \%$ CI $1 \cdot 1,2 \cdot 5 \%)$, respectively.

Table 1 shows the prevalence of obesity and sleep deprivation levels I and II in the workers according to sociodemographic characteristics, parental excess weight, behavioural traits and work shift. Obesity was more prevalent in the participants who were female, aged 40 years and older, had less schooling and reported excess weight in both parents. Sleep deprivation levels I and II were associated with increased income, number of meals consumed throughout the day and nightshift work. All of the workers who exhibited a degree of sleep deprivation worked the night shift.

Table 2 describes the associations between the different levels of sleep deprivation and obesity. The workers who reported a degree of sleep deprivation had a higher prevalence of obesity, which is an independent effect that increased after adjusting for possible confounding factors. After controlling for sociodemographic characteristics, parental excess weight, behavioural traits and work shift, the prevalence ratios were $1 \cdot 4(95 \%$ CI $0 \cdot 8,2 \cdot 2)$ and $4 \cdot 4$ (95\% CI $2 \cdot 4,8 \cdot 0)$ in the workers with sleep deprivation levels I and II, respectively, compared with the reference group ( $>5 \mathrm{~h}$ of continuous sleep/d). 
Table 1 Prevalence and $95 \%$ confidence interval of obesity* and sleep deprivation level I and IIt according to sociodemographic, hereditary and behavioural characteristics among shift workers in southern Brazil, January-May 2010

\begin{tabular}{|c|c|c|c|c|c|c|c|c|}
\hline \multirow[b]{2}{*}{ Variable $(n)$} & \multicolumn{2}{|c|}{ Obesity } & \multirow[b]{2}{*}{$P \ddagger$} & \multicolumn{2}{|c|}{ Sleep deprivation level I } & \multicolumn{2}{|c|}{ Sleep deprivation level II } & \multirow[b]{2}{*}{$P \ddagger$} \\
\hline & $\%$ & $95 \% \mathrm{Cl}$ & & $\%$ & $95 \% \mathrm{Cl}$ & $\%$ & $95 \% \mathrm{Cl}$ & \\
\hline Sex & & & 0.016 & & & & & 0.342 \\
\hline Male (304) & $7 \cdot 2$ & $4 \cdot 3,10 \cdot 1$ & & $16 \cdot 4$ & $14 \cdot 1,21 \cdot 6$ & $1 \cdot 0$ & $0 \cdot 1,3 \cdot 4$ & \\
\hline Female (601) & $12 \cdot 4$ & $9 \cdot 8,15 \cdot 1$ & & $18 \cdot 8$ & $15 \cdot 7,21 \cdot 3$ & $2 \cdot 0$ & $1 \cdot 0,3 \cdot 2$ & \\
\hline Age & & & 0.001 & & & & & 0.585 \\
\hline $18-22$ years $(164)$ & $5 \cdot 4$ & $1 \cdot 9,9 \cdot 0$ & & $16 \cdot 3$ & $12 \cdot 0,21 \cdot 5$ & $2 \cdot 4$ & $0 \cdot 1,5 \cdot 1$ & \\
\hline $23-26$ years (189) & $7 \cdot 9$ & $4 \cdot 0,11 \cdot 8$ & & $20 \cdot 1$ & $15 \cdot 4,25 \cdot 6$ & $1 \cdot 1$ & $0 \cdot 0,3 \cdot 4$ & \\
\hline $27-31$ years (158) & $12 \cdot 6$ & $7 \cdot 4,17 \cdot 8$ & & $16 \cdot 9$ & $12 \cdot 2,22 \cdot 6$ & $1 \cdot 8$ & $0 \cdot 1,4 \cdot 6$ & \\
\hline $32-39$ years (209) & $11 \cdot 0$ & $6 \cdot 7,15 \cdot 2$ & & $22 \cdot 0$ & $17 \cdot 0,27 \cdot 6$ & $1 \cdot 2$ & $0 \cdot 2,3 \cdot 5$ & \\
\hline $40-50$ years $(185)$ & $16 \cdot 2$ & $10 \cdot 8,21 \cdot 6$ & & $10 \cdot 7$ & $7 \cdot 1,15 \cdot 4$ & $2 \cdot 6$ & $0 \cdot 1,0.5$ & \\
\hline Marital status & & & 0.053 & & & & & 0.085 \\
\hline Having a partner (273) & $7 \cdot 7$ & $4 \cdot 5,10 \cdot 8$ & & $13 \cdot 9$ & $10 \cdot 0,18 \cdot 0$ & $2 \cdot 2$ & $0 \cdot 1,4 \cdot 7$ & \\
\hline Not having a partner (632) & $12 \cdot 0$ & $9 \cdot 4,14 \cdot 5$ & & $19 \cdot 7$ & $16 \cdot 7,23 \cdot 1$ & $1 \cdot 4$ & $0 \cdot 1,2 \cdot 6$ & \\
\hline Skin colour & & & $0 \cdot 751$ & & & & & $0 \cdot 494$ \\
\hline White (773) & $10 \cdot 6$ & $0 \cdot 8,12 \cdot 7$ & & $17 \cdot 6$ & $15 \cdot 0,20 \cdot 4$ & $3 \cdot 5$ & $2 \cdot 3,5 \cdot 0$ & \\
\hline Other (132) & $11 \cdot 5$ & $5 \cdot 9,17 \cdot 1$ & & $20 \cdot 8$ & $14 \cdot 1,28 \cdot 7$ & $0 \cdot 1$ & $0 \cdot 0,4 \cdot 2$ & \\
\hline Schooling & & & 0.007 & & & & & 0.596 \\
\hline $1-4$ years of elementary school (116) & $15 \cdot 6$ & $10 \cdot 0,21 \cdot 2$ & & $18 \cdot 7$ & $13 \cdot 0,25 \cdot 4$ & $1 \cdot 8$ & $0 \cdot 1,5 \cdot 2$ & \\
\hline $5-8$ years of elementary school (228) & $12 \cdot 3$ & $8 \cdot 0,16 \cdot 5$ & & $15 \cdot 3$ & $10 \cdot 9,20 \cdot 7$ & $1 \cdot 3$ & $0 \cdot 0,3 \cdot 8$ & \\
\hline Did not complete high school (72) & $6 \cdot 9$ & $0 \cdot 9,13 \cdot 0$ & & $12 \cdot 5$ & $5 \cdot 8,22 \cdot 4$ & $2 \cdot 7$ & $0 \cdot 3,9 \cdot 6$ & \\
\hline Completed high school and higher (435) & $8 \cdot 4$ & $5 \cdot 8,11 \cdot 0$ & & $20 \cdot 1$ & $16 \cdot 4,24 \cdot 1$ & $1 \cdot 6$ & $0 \cdot 1,3 \cdot 2$ & \\
\hline Income quartile & & & 0.323 & & & & & 0.042 \\
\hline I (208) & $8 \cdot 2$ & $4 \cdot 4,11 \cdot 9$ & & $13 \cdot 9$ & $9 \cdot 5,19 \cdot 4$ & $1 \cdot 0$ & $0 \cdot 0,3 \cdot 4$ & \\
\hline II (223) & $9 \cdot 8$ & $5 \cdot 9,13 \cdot 8$ & & $18 \cdot 8$ & $14 \cdot 0,24 \cdot 6$ & $1 \cdot 8$ & $0 \cdot 1,4 \cdot 5$ & \\
\hline III (235) & $14 \cdot 0$ & $9 \cdot 5,18 \cdot 5$ & & $18 \cdot 3$ & $13 \cdot 5,23 \cdot 8$ & $1 \cdot 3$ & $0 \cdot 0,3 \cdot 6$ & \\
\hline IV (228) & $10 \cdot 5$ & $6 \cdot 5,14 \cdot 5$ & & $21 \cdot 0$ & $16 \cdot 0,27 \cdot 0$ & $2 \cdot 2$ & $0 \cdot 1,5 \cdot 0$ & \\
\hline Parental overweight status & & & $<0.001$ & & & & & 0.793 \\
\hline Neither parent (669) & $7 \cdot 0$ & $5 \cdot 1,8 \cdot 9$ & & $18 \cdot 1$ & $15 \cdot 2,21 \cdot 2$ & 1.5 & $0 \cdot 1,2 \cdot 7$ & \\
\hline One parent (193) & $19 \cdot 7$ & $14 \cdot 2,25 \cdot 3$ & & $16 \cdot 1$ & $11 \cdot 2,22 \cdot 0$ & $2 \cdot 1$ & $0 \cdot 1,5 \cdot 2$ & \\
\hline Both parents (39) & $28 \cdot 2$ & $13 \cdot 4,43 \cdot 0$ & & $23 \cdot 1$ & $11 \cdot 1,39 \cdot 3$ & $2 \cdot 6$ & $0 \cdot 0,13 \cdot 5$ & \\
\hline Physical activity & & & 0.951 & & & & & 0.447 \\
\hline Inactive (581) & $10 \cdot 6$ & $8 \cdot 1,13 \cdot 2$ & & $16 \cdot 9$ & $13 \cdot 9,20 \cdot 1$ & $1 \cdot 5$ & $0 \cdot 1,2 \cdot 9$ & \\
\hline Active (324) & $10 \cdot 8$ & $7 \cdot 4,14 \cdot 2$ & & $20 \cdot 1$ & $15 \cdot 8,24 \cdot 8$ & $1 \cdot 8$ & $0 \cdot 1,4 \cdot 0$ & \\
\hline Work shift & & & 0.526 & & & & & $<0.001$ \\
\hline Day (325) & $9 \cdot 8$ & $6 \cdot 6,13 \cdot 1$ & & 0 & - & 0 & - & \\
\hline Night (580) & $11 \cdot 2$ & $8 \cdot 6,13 \cdot 8$ & & $28 \cdot 1$ & $24 \cdot 4,32 \cdot 0$ & $2 \cdot 6$ & $1 \cdot 4,4 \cdot 2$ & \\
\hline Number of meals per day & & & 0.291 & & & & & $<0.001$ \\
\hline One or two (154) & $15 \cdot 6$ & $10 \cdot 0,212$ & & $13 \cdot 6$ & $8 \cdot 6,20 \cdot 1$ & $2 \cdot 6$ & $0 \cdot 1,6 \cdot 5$ & \\
\hline Three (459) & $12 \cdot 3$ & $8 \cdot 0,16 \cdot 5$ & & $14 \cdot 1$ & $11 \cdot 1,17 \cdot 7$ & $1 \cdot 3$ & $0 \cdot 1,2 \cdot 8$ & \\
\hline Four or more (292) & $8 \cdot 2$ & $5 \cdot 8,10 \cdot 6$ & & $26 \cdot 4$ & $21 \cdot 4,31 \cdot 9$ & $1 \cdot 7$ & $0.0,3.9$ & \\
\hline
\end{tabular}

${ }^{*} \mathrm{BMI} \geq 30 \mathrm{~kg} / \mathrm{m}^{2}$.

tSleep deprivation level I, $\leq 5 \mathrm{~h}$ of continuous sleep/d with some additional rest; sleep deprivation level II, $\leq 5 \mathrm{~h}$ of continuous sleep/d without any additional rest. $\ddagger P$ value from $\chi^{2}$ test.

Table 2 Crude and adjusted prevalence ratios of obesity $\left(\mathrm{BMI} \geq 30 \mathrm{~kg} / \mathrm{m}^{2}\right)$ on sleep deprivation adjusted for sociodemographic and behavioural characteristics among shift workers in southern Brazil, January-May 2010

\begin{tabular}{|c|c|c|c|c|c|c|c|c|c|c|c|c|}
\hline \multirow[b]{2}{*}{ Sleep } & \multicolumn{3}{|c|}{ Model 1} & \multicolumn{3}{|c|}{ Model 2} & \multicolumn{3}{|c|}{ Model 3} & \multicolumn{3}{|c|}{ Model 4} \\
\hline & PR & $95 \% \mathrm{Cl}$ & $P^{*}$ & PR & $95 \% \mathrm{Cl}$ & $P^{*}$ & PR & $95 \% \mathrm{Cl}$ & $P^{*}$ & $P R$ & $95 \% \mathrm{Cl}$ & $P^{*}$ \\
\hline $\begin{array}{l}\text { Reference category } \\
\text { Sleep deprivation level I } \\
\text { Sleep deprivation level II }\end{array}$ & $\begin{array}{l}1 \cdot 0 \\
1 \cdot 2 \\
4 \cdot 8\end{array}$ & $\begin{array}{c}- \\
0 \cdot 8,2 \cdot 0 \\
2 \cdot 7,8 \cdot 7\end{array}$ & 0.002 & $\begin{array}{l}1 \cdot 0 \\
1 \cdot 3 \\
4 \cdot 8\end{array}$ & $\begin{array}{l}\quad- \\
0 \cdot 7,2 \cdot 0 \\
2 \cdot 2,10 \cdot 0\end{array}$ & 0.003 & $\begin{array}{l}1 \cdot 0 \\
1 \cdot 3 \\
4 \cdot 6\end{array}$ & $\begin{array}{c}- \\
0.8,2 \cdot 0 \\
2 \cdot 5,8 \cdot 3\end{array}$ & 0.002 & $\begin{array}{l}1 \cdot 0 \\
1 \cdot 4 \\
4 \cdot 4\end{array}$ & $\begin{array}{c}- \\
0 \cdot 8,2 \cdot 2 \\
2 \cdot 4,8 \cdot 0\end{array}$ & 0.003 \\
\hline
\end{tabular}

PR, prevalence ratio; Model 1, crude analyses; Model 2, adjusted for demographic and socio-economic variables; Model 3 , adjusted for model 2 and parents' overweight; Model 4, adjusted for models 2 and 3 and behavioural variables (physical activity, number of meals per day, work shift and period in the current shift); sleep deprivation level $\mathrm{I}, \leq 5 \mathrm{~h}$ of continuous sleep/d with some additional rest; sleep deprivation level II, $\leq 5 \mathrm{~h}$ of continuous sleep/d without any additional rest. ${ }^{*} P$ value from Wald test.

\section{Discussion}

The main results show a positive association between sleep deprivation and obesity in workers after controlling for possible confounding factors. The workers with sleep deprivation level II ( $\leq 5 \mathrm{~h}$ of continuous sleep/d without additional rest) were more likely to be obese compared with the reference group ( $>5 \mathrm{~h}$ of continuous sleep/d). 
Several studies conducted in different populations have reported similar findings. In a systematic review of observational studies, Patel and $\mathrm{Hu}$ concluded that there is an independent association between shortened sleep duration and weight gain ${ }^{(12)}$. Gangwisch et al. analysed longitudinal data from the National Health and Nutrition Examination Survey (NHANES I) and found that the individuals who reported sleeping for less than $6 \mathrm{~h}$ per night had a higher BMI than individuals who slept for more than $6 \mathrm{~h}$ per night ${ }^{(13)}$. Patel et al. followed 68183 women for 16 years as a part of the Nurses' Health Study and found a dose-response association between sleep duration and weight gain, with the greatest average weight gain being observed in the women who slept for $5 \mathrm{~h}$ or less ${ }^{(15)}$. In Brazil, Moreno et al. described a greater prevalence of obesity in truck drivers who slept for less than 8 h per night ${ }^{(10)}$.

The mechanisms that link sleep deprivation to weight gain are still not clear. Acute exposure to sleep deprivation in man is associated with thermoregulatory effects and is related to a reduction in total energy expenditure $^{(16,17)}$. Individuals with sleep deprivation may increase their total energy intake due to the impact of sleep deprivation on the peripheral regulators of satiety. Several studies have associated sleep deprivation with reduced leptin and increased ghrelin levels and a consequent increase in appetite and weight gain ${ }^{(18,19)}$.

Regarding the factors associated with sleep deprivation in the present study, the only behavioural trait associated was the number of meals consumed throughout the day. Intake of four or more meals was associated with sleep deprivation level I, while intake of two or fewer meals was associated with sleep deprivation level II. Because the present study was cross-sectional, it is not possible to establish whether sleep deprivation influenced the number of meals consumed by the workers during the day or whether nutritional aspects led to sleep issues. However, reduced sleep duration is known to have consequences on individuals' social routines and lifestyles, particularly regarding dietary habits and level of physical activity. Although the influence of shortened sleep duration on dietary habits has not been well described in the literature, an increase in total energy consumption and a tendency to skip meals appear to be involved $^{(15,20-22)}$.

Sleep deprivation is one of the main consequences of shift work $^{(23)}$. In the present study, all of the workers who exhibited a level of sleep deprivation worked the night shift, which is characterized by being awake during periods that are physiologically allocated for sleep. Thus, it is difficult to distinguish between the role of sleep deprivation and the role of nightshift work on weight gain in this population because the observed weight gain could be due to a shortened sleep duration and disruption of the circadian rhythm. A recent systematic review investigated the effects of shift work on weight gain and found strong evidence indicating that shift work is an independent risk factor for weight gain. However, none of the articles included in that review investigated duration of sleep in the participants ${ }^{(24)}$. Canuto et al. suggested evaluating sleep deprivation as a possible factor mediating the association between shift work and metabolic disorders ${ }^{(25)}$.

The workers who reported greater income level had increased levels of sleep deprivation. One hypothesis is that these individuals work double shifts to increase their income. In addition to the nightshift job, they have another job during the day that prevents longer sleep duration. Our study measured the family income but did not investigate the workers' specific earnings.

These results must be interpreted within the context of several limitations. Because it was a cross-sectional study, exposure and disease were measured concurrently, and it is difficult to assess whether sleep deprivation led to obesity or obesity induced the development of sleep disorders. The study was conducted with fixed shift workers and cannot be extrapolated to rotating shift workers. The classification of different levels of sleep deprivation may be considered arbitrary because the definition of normal sleep duration varies from 6 to $9 \mathrm{~h} / \mathrm{d}$. However, metabolic disorders and weight gain have been observed in individuals who sleep for less than $6 \mathrm{~h}$ per night $^{(15,18)}$.

\section{Conclusion}

The present results show a strong association between sleep deprivation and obesity in shift workers. The study contributes to understanding the risk factors for obesity and sleep deprivation in shift workers. Future studies with different methodological designs and populations should be conducted to understand better the associations between shift work, sleep deprivation and excessive weight gain.

\section{Acknowledgements}

Sources of funding: This study was supported by the National Council of Technological and Scientific Development (CNPq; grant numbers 477069/2009-6 and 478366/2011-6). R.C. received a scholarship from the Brazilian Federal Agency for Support and Evaluation of Graduated Education (CAPES). M.T.A.O. and M.P.P. received research productivity grants from CNPq (grant numbers 304793/2010-8 and 303424/2011-7). The funders had no role in the study design, data collection and analysis, decision to publish and preparation or approval of the manuscript. Conflicts of interest: None. Autbors' contributions: All authors participated in the design, analysis and writing of the manuscript. 


\section{References}

1. Adams KF, Schatzkin A, Harris TB et al. (2006) Overweight, obesity, and mortality in a large prospective cohort of persons 50 to 71 years old. $N$ Engl J Med 355, 763-778.

2. Brazilian Institute of Geography and Statistics (2010) Household Budget Survey. Anthropometry and Nutritional Status of Children, Adolescents and Adults in Brazil. Brasilia: Brazilian Ministry of Health.

3. Cohen SS, Signorello LB, Cope EL et al. (2012) Obesity and all-cause mortality among black adults and white adults. Am J Epidemiol 176, 431-442.

4. Berrington de Gonzalez A, Hartge P, Cerhan JR et al. (2010) Body-mass index and mortality among 1.46 million white adults. $N$ Engl J Med 363, 2211-2219.

5. Calle EE \& Thun MJ (2004) Obesity and cancer. Oncogene 23, 6365-6378.

6. Eckel RH, York DA, Rössner S et al. (2004) Prevention conference VII: obesity, a worldwide epidemic related to heart disease and stroke: executive summary. Circulation 110, 2968-2975.

7. Cohen DA (2008) Obesity and the built environment: changes in environmental cues cause energy imbalances. Int J Obes (Lond) 32, Suppl. 7, S137-S142.

8. Straif K, Baan R, Grosse Y et al. (2007) Carcinogenicity of shift-work, painting, and fire-fighting. Lancet Oncol $\mathbf{8}$, 1065-1066.

9. Inoue Y, Hiroe Y, Nishida M et al. (2000) Sleep problems in Japanese industrial workers. Psychiatry Clin Neurosci 54, 294-295.

10. Moreno CR, Louzada FM, Teixeira LR et al. (2006) Short sleep is associated with obesity among truck drivers. Chronobiol Int 23, 1295-1303.

11. Ohayon MM, Smolensky MH \& Roth T (2010) Consequences of shiftworking on sleep duration, sleepiness, and sleep attacks. Chronobiol Int 27, 575-589.

12. Patel SR \& Hu FB (2008) Short sleep duration and weight gain: a systematic review. Obesity (Silver Spring) 16, 643-653.
13. Gangwisch JE, Malaspina D, Boden-Albala B et al. (2005) Inadequate sleep as a risk factor for obesity: analyses of the NHANES I. Sleep 28, 1289-1296.

14. World Health Organization (2011) Global Recommendations on Physical Activity for Health. Geneva: WHO

15. Patel SR, Malhotra A, White DP et al. (2006) Association between reduced sleep and weight gain in women. $A m J$ Epidemiol 164, 947-954.

16. Benedict C, Hallschmid M, Lassen A et al. (2011) Acute sleep deprivation reduces energy expenditure in healthy men. Am J Clin Nutr 93, 1229-1236.

17. Knutson KL, Spiegel K, Penev P et al. (2007) The metabolic consequences of sleep deprivation. Sleep Med Rev 11, 163-178.

18. Chaput J-P, Despres J-P, Bouchard C et al. (2007) Short sleep duration is associated with reduced leptin levels and increased adiposity: results from the Quebec Family Study. Obesity (Silver Spring) 15, 253-261.

19. Taheri S, Lin L, Austin D et al. (2004) Short sleep duration is associated with reduced leptin, elevated ghrelin, and increased body mass index (BMI). Sleep 27, 146-147.

20. Brondel L, Romer MA, Nougues PM et al. (2010) Acute partial sleep deprivation increases food intake in healthy men. Am J Clin Nutr 91, 1550-1559.

21. Nishiura C, Noguchi J \& Hashimoto H (2010) Dietary patterns only partially explain the effect of short sleep duration on the incidence of obesity. Sleep 33, 753-757.

22. Nedeltcheva AV, Kilkus JM, Imperial J et al. (2009) Sleep curtailment is accompanied by increased intake of calories from snacks. Am J Clin Nutr 89, 126-133.

23. Ramey SL, Perkhounkova Y, Moon M et al. (2012) The effect of work shift and sleep duration on various aspects of police officers' health. Workplace Health Saf 60, 215-222.

24. van Drongelen A, Boot C, Merkus S et al. (2011) The effects of shift work on body weight change - a systematic review of longitudinal studies. Scand J Work Environ Health 37, 263-275.

25. Canuto R, Garcez AS \& Olinto MT (2013) Metabolic syndrome and shift work: a systematic review. Sleep Med Rev (Epublication ahead of print version). 